\title{
تدريس مهارة الكلام في ضوء نظرية الذكاءات المتعددة \\ (بالنطبيق على تلاميذ مدرسة أناك صالح الابتدائية مالانج جاوى شرقية)
}

\author{
Abdul Basid \\ الجامعة الاسلامية الحكومية مولانا مالك إبراهيم مالانج \\ abdulbasid@bsa.uin-malang.ac.id
}

\begin{abstract}
This reserach elaborates on the Arabic instruction, especially speaking skill based on Multiple Intelligences Theory. The research problems are: (1) what is the process of Arabic instruction based on Multiple Intelligences; and (2) what is the effectiveness of the use of Multiple Intelligence Theory in Arabic instruction, specially speaking skill. The design of this study is experimental study. Thus to get a focus, the researcher determines to use population and sample only for students who have word smart and auditory learning style by applying Multiple Intelligences Research. The result of this study is: (1) the process of speaking skill based on Multiple Intelligences Theory consist of personality, guideline (title, material, competence standard, indicator, period), procedure (scene setting, preface activity, main activity, closing activity), evaluation; (2) the result of speaking skill by using Multiple Intelligences theory in post test in experiment group is mean 79,16 , paired different mean 23,33 , standard deviation 7,35, standard error 3,00, t-test 5,534 and significant value 0,003 and the effectively level of the use of Multiple Intelligences theory in speaking skill is t-test 5,534, this level is higher than t-table $1 \%(2,11)$ and $5 \%(2,29)$.
\end{abstract}

الكليمات الرئيسية: الذكاء، جوانب الذكاءات المتعددة، مهارة الكلام

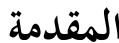

$$
\begin{aligned}
& \text { إن نحن نلاحظ ونتعمق عملية التدريس، فنجد هناك عمليتان، الأولى هي كيف يعلّم } \\
& \text { المدرس، والثانية هي كيف يتعلم التلاميذ. تختلفنّ عملية التعليم وعملية التعلم. إن التعليم هو } \\
& \text { مساعدة التلاميذ للحصول على المعلومات والأفكار والمهارات والقيم والتفكيرات والوسائل } \\
& \text { لتحقيق نفسه والطرائق كيف هم يتعلمون (Uno and Umar, 2010:4). وأما التعلم هو التغيير في } \\
& \text { شخصية التلاميذ، ويعبر هذا التغيير بترقية جودة السلوك وكميتهم، المثال ترقية الكفاءات } \\
& \text { والمهارات والمواقف والعادات والمفاهيم والكفاءات الأخرى (1) :Hakim, 2005). } \\
& \text { على المدرس الذي يريد أن يطور ميول التلاميذ فلابد عليه أن يعرف دنيا التلاميذ } \\
& \text { بالشكل الجيد، وأن يفهم مشكلاتهم والطريقة لحلها، وأن يعامل معهم، وأن يحسّن دنياهم. }
\end{aligned}
$$


يحتاج كل هذا لأجل التلاميذ يجدون معاملة جيدة ويكونون في المكان الصحيح حتى يكون

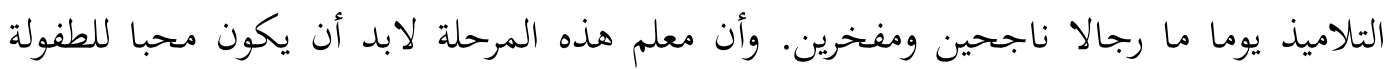

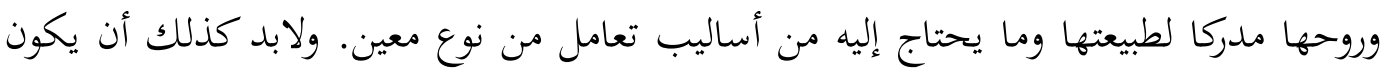
قادرا على أن يعيش جو التلاميذ وحياتهم، وأن يشارك ألعابهم وحركاتهم.

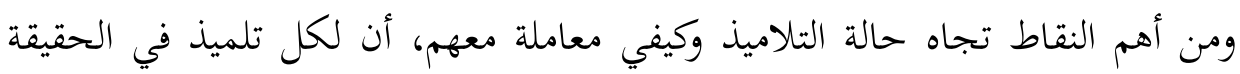

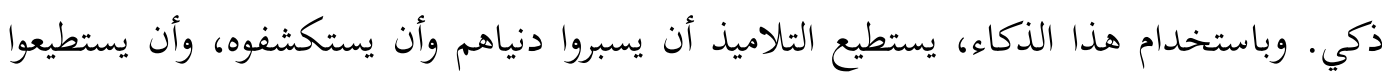

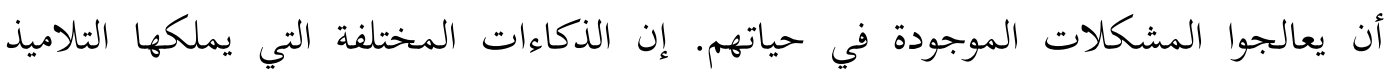
ستكون طريقة في التعلم. المقصود بمفهوم الذكاء في الفقرة السابقة هي الذكاء كما يعبره غاردنر. يؤكد غاردنر أن

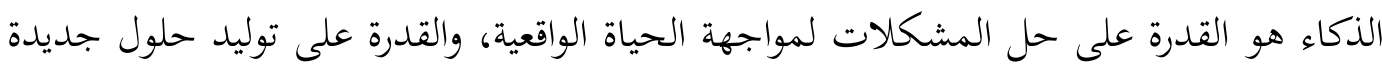

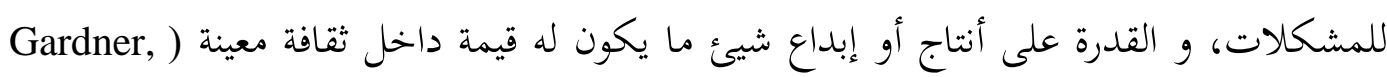
(1993:7 يعبر غاردنر أن كل التلميذ ذو طريقة مختلفة لأن يكون ماهرا أو ذاكيا: اللغة والرقم

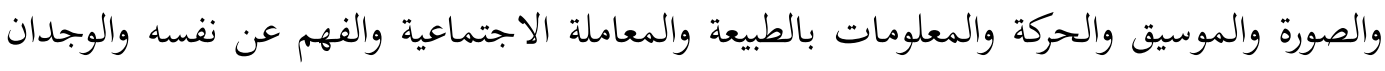
(Armstrong, 2002: 2-4; 2005:4)

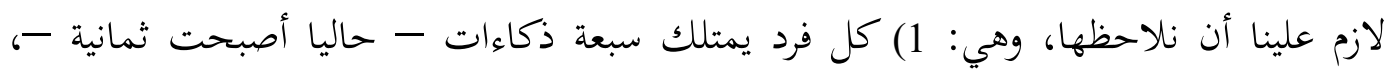
ولكن الأفراد يختلفون في نسبة وجود كل ذكاء لديهم، 2) معظم الناس يستطيعون تطوير كل ذكاء

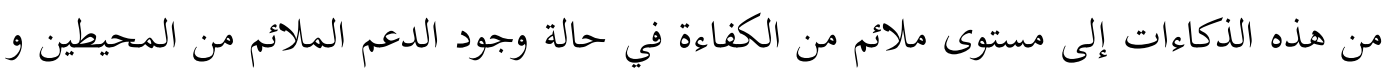

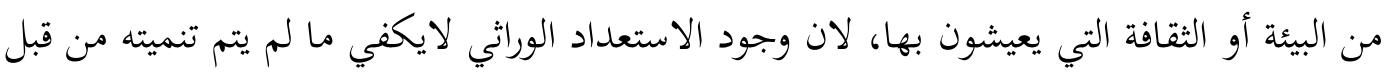

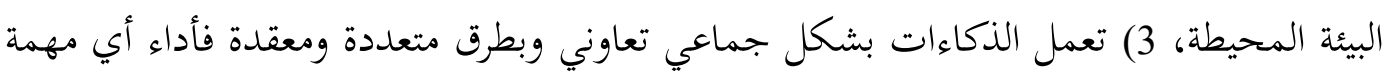
ولو كانت بسيطة يتطلب تعاون أكثر من ذكاء لإنجازها الأمر يؤكد الاستقلالية النسبية لهذه تهاه

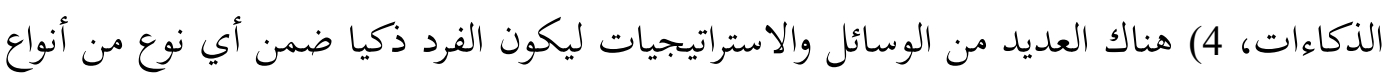
الذكاءات المتعددة (Armstrong, 2002:16-18).

إن نظرية الذكاءات المتعددة هي التقييم الذي يصف حالة التلاميذ في استخدام

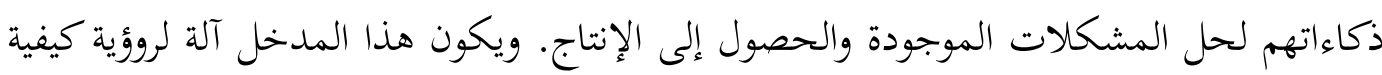

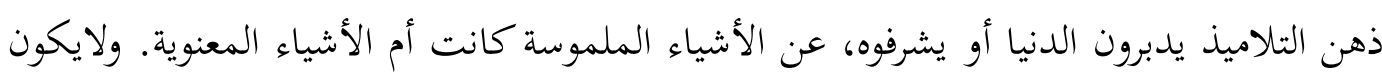

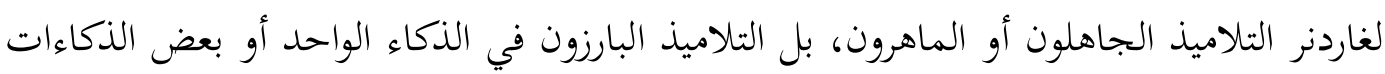

.(Sujiyono, 2010: 49) 
وانطلاقا من الفكرة الإيجابية التي تقول بأن كل التلميذ ذو ذكاءات متعددة فلابد على المدرس أو المربي أن يسعى وأن يبتدع البيئات والمحفزات التي تشجع على تطوير ذكاءات التلاميذ المتعددة. ومن المعروف بأن نقصان البيئة المشجعة لدي تطوير ذكاءات التلاميذ

المتعددة مؤثر تجاه فعال مخ التلاميذ أو دماغهم (Eggen and Kauchak, 2004: 1999). وفي المرات العديدة، لابد علينا أن نتذكر أن الطفل هو الإنسان الذي يكون تحت عملية التنمية والتطوير من خلال عقله وجسده للحصول على أهداف تربيته في المؤسسات التربوية (Muhaimin and Mujib, 1993: 177). والمعنى من هذه الفكرة هي الطفل لم يصل إلى العمر البالغ وهو يحتاج إلى الأخرين لكي يكون بالغا. ينتمي الطفل ويطور بالنسبة إلى كفاءاته النفسية. وانطالاقا من الأفكار السابقة، كالمربي والمشرف لابد علينا أن نتجنب النظرة أو الفكرة أن هذا الطفل ذكي وذلك الطفل جاهل. لازم علينا أن نعتقد بأن كل طفل ذكي. لا طفل جاهلا. إذن ينبغي علينا أن نغير كيفيتنا وتفكيرنا في النظر إلى الذكاء. الطفل الذي نفترضه جاهلا كأنه الطفل المعان والمسكين لأنه لم يجد المدرس أو المربي أو المشرف الذي يستطيع أن يدرس أو أو

أن يربي أو أن يشرف بالطريقة التي تساوي بطريقة تعلمه (1) (Gunawan, 2004).

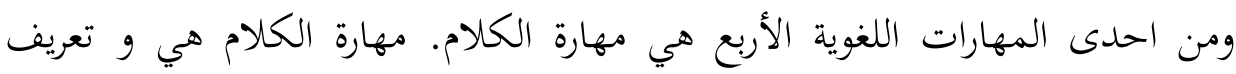
الكلام عند الدكتور أحمد فؤاد عليان هو: ما يصدر عن الإنسان من صوت يعبر به عن شيئ له دلالة في ذهن المتكلم والسامع، أو على الأقل في ذهن المتكلم. وبناء على هذا، فإن الكلام الذي ليس له دلالة في ذهن المتكلم أو السامع، لايعد كلاما، بل هي أصوات لامعنى لها (عليان،

وانطالاقا من أهمية وجود نظرية الذكاءات المتعددة في تدريس اللغة العربية لاسيما مهارة الكلام الفعّالة والجذّابة والمناسبة، أقام الباحثان بحثا تحت الموضوع تدريس مهارة الكلام على لهيل ضوء نظرية الذكاءات المتعددة في مدرسة أناك صالح الابتدائية. وقدم الباحثان أسئلة البحث كالتالي: 1) كيف يتمّ تطبيق نظرية تعدد الذكاء في تنمية مهارة الكلام لطلبة مدرسة أناك صالح الابتدائية مالانج؟، 2) ما مدى فعّالية تطبيق نظرية تعدد الذكاء في تنمية مهارة الكلام (الحوار البسيط) لطلبة مدرسة أناك صالح الابتدائية مالانج؟.

\section{نظرية الذكاءات المتعددة}

الذكاء هو تعبير عن عقول الناس الذي يمكن استخدامها كما طرائق في التعلم. الذكاء

بالنسبة إلى الشخص له فوائد عظيمة لنفسه، ومشاركته في المجتمع. من خلال مستوى عال من الذكاء أن يكون شخص مقدرا في المجتمع إذا كان الشخص قادرا على المشاركة في خلق 
الأشياء الجديدة الظاهرة. لا ينظر غاردنر الذكاء البشري على أساس الدرجات وحدها، أوالأشياء التي يمكن أن نراها ونحسبها، بل يمكن أن نعرف الذكاء بمعيار الكفاءة التالية: (1) الكفاءة لحل المشكلات، (2) الكفاءة للحصول إلى المشكلات الجديدة ولحلها، (3) الكفاءة لجعل Gunawan, 2004: 106; Musfiroh, 2008: 36; ) الأشياء أو إعطاء الجائزة لثقافة الناس

.(Sujiyono, 2010: 48 نقد غاردنر الافتراضات الشائعة عن الذكاء البشري في بحثه أن صفة الذكاء البشري هي Campbell et. all, 2004: 1; Sujiyono, ) الوحدات، وكل الفرد ذكي، ويمكن أن نحسب ذكاءه 48 :2010). عبر غاردنر في بحثه عن الذكاء بأن لكل إنسان ذكاءات متعددة واستخدمها البشر في الطرائق المختلفة والفريدة، يمكن لكل شخص أن يرقي الذكاء لتحقيق مستوى مناسب، وكل الذكاء يتعامل. إن الذكاءات المتعددة هي تقييم وصفي لمعرفة كيف يمكن للفرد أن يستخدم ذكائه لحل المشاكل ولإنتاج الشيء (Sujiyono, 2010:49). يكون هذا المنهج أداة لنرى كيف يعمل العقل البشري في العالم، سواء كانت أشياء ملموسة أو أشياء مجردة. رأى غاردنر أن كل الطفل ذكي، لايكون الطفل الجاهل. واستنادا إلى هذا الرأي، ينبغي على الآباء والمعلمين أن يكونوا محذرين ومدققين في لهان تقييم ذكاء الأطفال وتحفيزه في عملية التعلم. وبالتالي أساس التفكير لتنمية الذكاء في التعلم هو

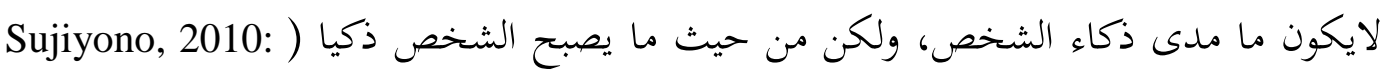

وأما خصائص نظرية الذكاءات المتعددة هي 1) تختلف الذكاءات بعضها بعض الآخرى بل أنها تكون في نفس المستويات، 2) تختلف درجة الذكاءات المتعددة بعضها بعض الآخرى. يمكن أن نطور جميع الذكاءات المتعددة ونركزها، 3) هناك مؤشرات كثيرة لكل ذكاء. يمكن الشخص أن يركز قوة الذكاء الواحد ويفقد نقاط ضعفها من سبيل التمرينات أوالتدريبات، 4) تعمل جميع الذكاءات لتحقيق الأنشطة البشرية التي يقيم بها البشر. يمكن النشاط الواحد أن يحتاج إلى الذكاء الواحد أو أكثر منه، ويستطيع الشخص أن يستخدم الذكاء الواحد في المجال المتنوعة، 5) توجد الذكاءات المتعددة في أنحاء الثقافات والأعمار في هذا العالم، 6) تبدا مراحل الذكاءات الطبيعية بتكوين الأشكال الأساسية. على سبيل المثال، يتميز الذكاء الموسيقي بكفاءة لتفريق نبرة، وأما الذكاء المكاني يتميز يكفاءة ترتيب الأمكنة المتنوعة، 7) يعبر الذكاءات في المرحلة المراهقة بتحقيق المهن والهوايات. على سبيل المثال، يصل الذكاء الرياضي المنطقي في المرحلة العالية بوجود المهن مثل أهل علم الرياضيات أوأهل علم الحاسوب أوأهل العلوم 
الأخرى، 8) يمكن الطفل أن يكون في المرحلة المنخفضة من ناحية الذكاءات المعينة طول

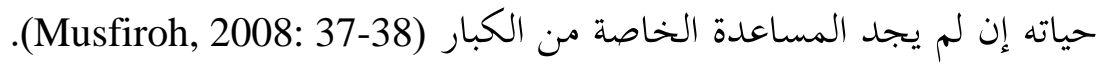

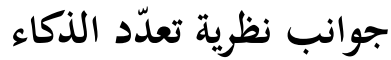

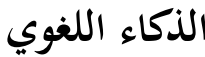

إن الذكاء اللغوي هو الذكاء في معالجة الكلمات أو القدرة على استخدام الكلمات

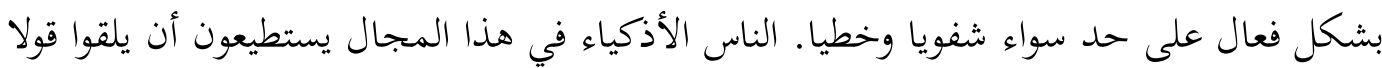
ممتازا ويقنعوا الأخرين ويسلوا الأشخاص ويعلموا تعليما فعالا من خلال الكلمة المنطوقة (Sujiyono, 2010:55). يشمل هذا الذكاء أربع المهارات اللغوية هي الاستماع والكلام والقراءة والكتابة.

يحتوي هذا الذكاء بالعناصر الكثيرة ومنها علم الأصوات والغة والدلالة والفراكماتيك (Armstrong, 2002: 20). الناس الذين يتميزون بالذكاء اللغوي لهم حساسية حريصة على

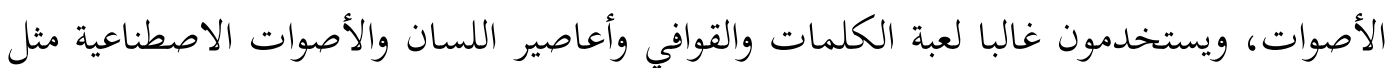
الأجراس وغيرها.

إن الأغراض من التنمية اللغوية هي: (1) يقدر الأطفال على التواصل شفهيا وتحريريا

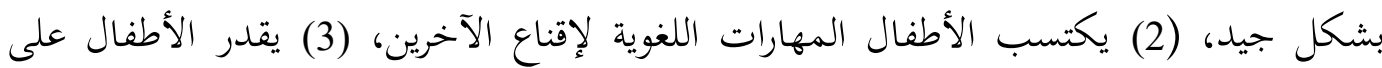

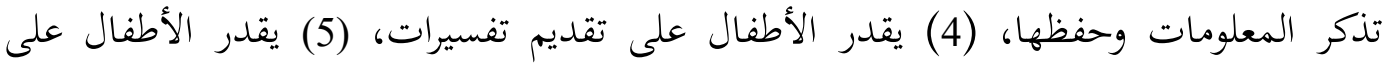
مناقشة اللغة ذاتها (Campbell et. all, 2004: 57). إن مواد البرنامج في المناهج الدراسية التي يمكن أن تتطور الذكاء اللغوي وإدخال الحروف والأصوات والإملاء والقراءة والكتابة والاستماع والكلام أو المناقشة وتقديم التقرير شفهيا

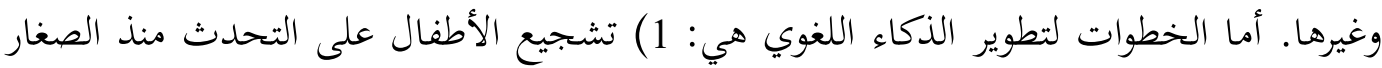

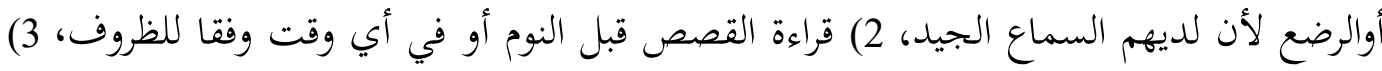

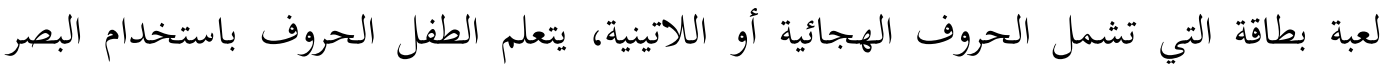

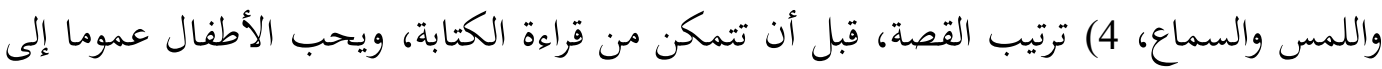
"قراءة الصور." أعط الأطفال قطعة وادعهم لتعبير رأيه عن الصورة المعينة، 5) المناقشة عن الأشياء

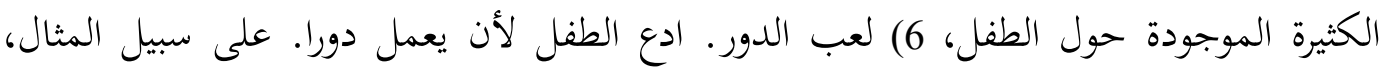

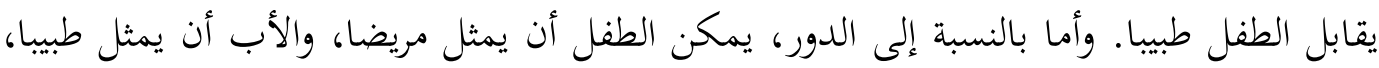


7) الاستماع إلى الأغاني السعيدة. ادع الطفل أن يغني لأنه يحب الغناء. يشجع هذا النشاط دقة سماع الطفل وملاحظته (58)-58) : الذكاء المنطقي والرياضي إن الذكاء المنطقي الرياضي هو الذكاء في العدد والمنطقي. يرتبط هذا الذكاء كفاءة تنظيم الكلمات أو المهارة لاستخدام المنطق أو المخ الصحيح. الأغراض من مواد البرامج في المناهج الدراسية التي يمكن أن يتطور الذكاء المنطقي الرياضي هي اعتراف الأرقام وبعض الأنماط والحساب والقياس والهندسة والاحصاء والفرص وحل المشكلات والمنطق وألعاب استراتيجية أو مؤشر الرسم البياني.

الخطوات لتطوير الذكاء المنطقي الرياضي هي: 1) لعبة التركيب والسلم والثعبان وغيرها. يشجع هذا اللعب طفلا لترقية كفاءة حل المشكلات باستخدام المنطق، 2) الاعتراف على الأشكال الهندسية، ويمكن أن تبدأ الأنشطة البسيطة للطفل منذ الصغار. على سبيل المثال، أن نضع الأشكال الهندسية المختلفة الملونة على سرير الطفل، 3) إدخال الأرقام من خلال القوافي والأغاني، 4) استكشاف الأفكار من خلال المناقشة، مثل ربط أنماط من العلاقات بين السبب والنتيجة أو المقارنة، ولعبة التخمين من الأرقام وغيرها، 5) إدخال أنماط، واللعبة لتكوين الأنكاط المعينة باستخدام الأزرار الملونة، والملاحظة على الأحداث اليومية بحيث يمكن لطفل أن يفهمها، 7) إثراء تجربة التفاعل مع المفاهيم الرياضية، على سبيل المثال، دعوة الطفل إلى التسوق، وإعطاء الفرصة للمساعدة في التحقق من البنود التي تم تضمينها في عربة التسوق، والنظر في حجم البضائع الثقيلة التي نشتريها، واختيار الخضروات والفواكه التي يطبخها الأم في المطبخ (Sujiyono, 2010: 57-58).

\section{الذكاء البصري والمكاني}

إن الذكاء البصري والمكاني هو القدرة على تصور الصور في ذهن الشخص. يستخدم الأطفال هذا الذكاء للتفكير في شكل التصور والصور لحل مشاكل أو بحث الإجابة. أوضح كامبل وكامبل وديكنسون في سوجيانا وسوجيانا أن أهداف مواد البرامج في المهنج الدراسية التي يمكن أن تنطور الذكاء البصري المكاني هي الفيديو وصورة ونموذج أو الرسوم البيانية.

إن الخطوة لتطوير الذكاء البصري والمكاني هي: 1) السطر. بدأ الطفل أن يرسم سطرا، وكان عمره ثمانية عشر شهرا. يحقق رسم سطر الطفل تعبير نفسه. ولو كان السطر لم يكن تعبير 
فكره. يدرب هذا النشاط تفاوق بين اليد والعين، 2) الرسم. يمكن أن نعمل الرسم في أي مكان ووقت، وكان أجرته رخيص. أعط الفرصة لكي يرسم الأشياء التي يريدون وفقا بتخيله وابتكاره، 3) النشاط لصناعة الفن أو الحرفة الذي يتطلب قدرة الطفل على التعامل مع المواد. يتدرب هذا ئري النشاط ابداع الأطفال وخيالهم. وبالإضافة إلى ذلك ، يمكن للأطفال أن يقوي تفائلهم، 4) زيارة الأماكن المختلفة. يمكن لهذه الأنشطة إثراء تجربة بصرية مثل زيارة المتاحف وحدائق الحيوان والسفر إلى العالم الطبيعي، 5) إجراء لعبة البنائية والابتكارية. ومن الأمثلة من هذا النوع هي بناء البناء باستخدام شعاع ومتاهات وألغاز وفيديو والفلم والخرائط والصور والشرح، 6) التنظيم والتصميم .يمكن أن نطور دقة الطفل في التنظيم والتصميم في أنشطة مجموعة مساحة في المنزل، مثل ترتيب غرفة النوم (54-59) :Sujiyono, 2010).

الذكاء الحركي إن الذكاء الحركي هوالذكاء الذي يستخدمه الشخص، فهو يستطيع أن يحرك أعضاء جسمه مثل الجري والرقص وبناء الأشياء ، والقيام بأنشطة الفن وغيرها. أغراض مواد البرامج في المناهج الدراسية التي يمكن أن تتطور الذكاء الحركي هي مجموعة متنوعة من الأنشطة البدنية، وأنواع مختلفة من الرياضة والرقص ولغة الجسم.

الخطوات لتطوير الذكاء الحركي هي: 1) الرقص. يحب الأطفال رقصا. يمكن أن ندعو

الطفل لرقص جماعة لأن يتطلب الرقص توازنا وانسجاما في حركة الجسم، والقوة، ومرونة العضلات، 2) لعب دور أو دراما. يدفع هذا اللعب ذكاء الطفل الحركي. يتطلب هذا النشاط طفلا لاستخدام جسمه وفقا بدوره وكيفية تعبير النفس. إضافة على ذلك، يشجع هذا النشاط الكفاءة الاتصالية في المجتمع لأن هذا النشاط يتطلب الطفل بالمشاركة مع الأخرين، 3) ممارسة المهارات البدنية. تساعد ممارسة الرياضة البدنية المختلفة لترقية المهارات الحركية للأطفال. على بلى سبيل المثال، المشي على ألواح خشبية. ويمكن أن يتم هذا النشاط في ثلاث سنوات من عمر الأطفال .وبالإضافة إلى تدريب القوة العضلية ، يدرب هذا النشاط لمعرفة الرصيد، 4) الرياضة. تدفع الأنشطة الرياضية لتحسين الصحة والنمو. وينبغي إجراء الرياضية وفقا لتطوير محرك الأطفال، مثل السباحة وكرة القدم وكرة الريشة وغيرها (60-59jiyono, 2010: 
إن الذكاء الموسيقي هو الذكاء لفهم الأنشطة الموسيقية، من خلال تمتع الموسيقا، ونقد الموسيقا، وتغيير نبر، وتعبير الشعر في الغناء. تشمل هذا الذكاء من النبر والتنغيم ونوع الغناء. أهداف مواد البرامج في المنهج الذي يطور الذكاء الموسيقي هي استماع الموسيقا، والنبر والتنغيم، والآلات الموسيقية، والغناء الجماعي أوالفردي.

أما الخطوات لتطوير الذكاء الموسيقي هي: 1) أعط طفلا فرصة لمعرفة كفاءته النفسية، اجعله متفائلا. على سبيل المثال، أعط السؤال "من يحب الموسيقى؟، ثم "من يحب أن يعمل بالآلات الموسيقية؟". وبعد هذا العمل، طور فهم الموسيقى لدى الطفل، 2) اجعل الأنشطة الخاصة التي يطور الذكاء الموسيقي. على سبيل المثال، "يوم المهنة" الذي يقص فيه الموسيقون عن ذكائهم الموسيقي، والرحلات الميدانية إلى محطة راديو ويسمع فيه الأطفال بعض الأغاني من فنانين معروفين، وسير الأغاني وغيرها، 3) الخبرة العملية التجريبية. اجعل الجائزة للأعمال التي ينتجها الأطفال، مثل اجعل الرفوف للمعارض أو العروض الفنية، 4) تشجيع الأطفل على أغنيات بكلمات بسيطة مع إيقاع التواقيع السهلة لالتابعة (61-60 :Sujiyono, 2010).

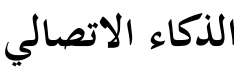

إن الذكاء الاتصالي هو التفكير من خلال التواصل والتفاعل مع الآخرين. أما بالنسبة للأنشطة التي تشمل هذا الذكاء هو القيادة والتنظم والتفاعل والمشاركة والحب والحديث والاجتماع واللعب في المجموعات والنوادي والأصدقاء والمجموعات والتعاون. أغراض مواد البرامج في المناهج الدراسية لتطوير الذكاء الذكاء الاتصالي هي التعلم في المجموعة والعمل على المشروع وتسوية الصراعات وتواصل إلى التوافق والمسؤولية عن نفسك والمشاركة في الحياة الاجتماعية ،و إدخال تعبيرات الآخرين ومشاعرهم. إن الخطوات لتطوير الذكاء الاتصالي لدي الأطفال هي: 1) تطوير دعم المجموعة، 2) وضع مدونة قواعد السلوك، 3) توفير المسؤولة في المنزل، 4) حل النزاعات جماعة، 5) الممارسة بالأنشطة الاجتماعية في البيئة، 6) احترام الاختلاف في الرأي بين الطفل وأصدقائه، 7) تعزيز موقف ودية وفهم التنوع الثقافي في البيئة الاجتماعية، 8) تدريب الصبر على الانتظار حتى يأتي الدور، 9) الحديث والاستماع الى خطاب الآخرين (61-60 :Sujiyono, 2010). 
إن الذكاء النفسي هو القدرة على التفكير العاكس، الذي يشير إلى الوعي العاكس عن

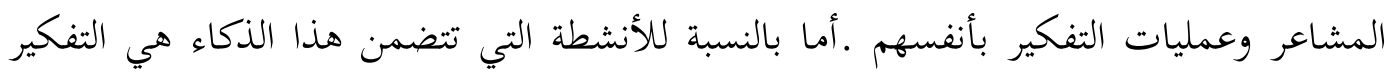
والتأمل والحلم والانسحاب وإنشاء المجلات وتقييم النفس وكتابة التأمل. أغراض مواد البرامج في المناهج الدراسية التي يمكن أن تتطور الذكاء النفسي هي ردود الفعل والمشاعر وتحليل الذات والثقة بالنفس والإعجاب الذاتي وتنظيم الوقت والتخطيط للمستقبل.

إن الخطوات لتطوير الذكاء النفسي لدي الأطفال هي: 1) خلق صورة ذاتية إيجابية ، مثل الجملة "أنا ولدا طيبا" وغيرها، 2) يمكن المتعلمون أن يوفروا صورة الذاتية الجيدة عن النفس لدى الأطفال عن طريق عرض موقف جيدة حتى يكون الأطفال لا يزالوا من الموقف المحترم، 3) خلق جو صاف وظروف مواتية في المنازل والمدارس التي تدعم تنمية المهارات النفسية لدي الأطفال، 4) كتابة الشعور في المجلة الشخصية ، يجب أن يكون لكل طفل الخبرة معينة في أي وقت معين. أعط طفلا كتابا يوميا لكي يكتب مشاعره، ويمكن للأطفال أن يعبرواها في الكتابة أو الرسم، 5) المحادثة إلى نقاط الضعف ونقاط القوة والمصالح لدي الطفل. يمكن المعلم أن يسأل إلى الطفل عن شعوره، والأشياء التي تميزه، وما الأنشطة التي لا يرغب حاليا .مساعدة الأطفال للعثور على نقص نفسها ، مثل المواقف السلبية التي ينبغي تصحيحها، 6) تخيل نفسك في المستقبل .جعل المحادثة مع الطفل ، مثل ما إرادة الطفل إذا يبلغ في الكستقبل، 7) يشجع خيال الطلبة أن يكون الطلبة شخصية من القصة. نسمح الأطفال لكي يكونوا ممثلا يرغبوه

.(Sujiyono, 2010: 61-62)

الذكاء الطبيعي

إن الذكاء الطبيعي هو الذكاء على حب جمال الطبيعة من خلال مقدمة من النباتات

والحيوانات الموجودة في البيئة ملاحظة على الظواهر الطبيعية وحساسية على البيئة المحيطة. الغرض من مواد البرامج والمناهج الدراسية التي يمكن أن يتطور الذكاء الطبيعي هي العلوم البداية، وعلم النبات، والظواهر الطبيعية، أو العلاقات بين الكائنات الحية وغير الحية الموجودة في الطبيعة

حولها (Sujiyono, 2010: 62).

أما الطرائق لتطوير الذكاء الطبيعي هي: 1) يتمتع الجو في الطبيعة، مثل السفر إلى الحديقة أو الخيمة، 2) يتعلم الحيوانات، ويحافظها في البيت أو يسافر إلى حديقة الحيوانات، 3) يتعلم النباتات، ويحافظ النباتات في البيت، ويزور الحديقة ويهتم دورة نمو النباتات ونشأتها، 4) إنشاء مجلة عن الأحداث الطبيعية. يكتب الظواهر الموحودة التي تحدث وما أثرها تجاه 
أنفسنا، 5) تعلم الظواهر الطبيعية. يمكن أن نقيم بالملاحظة المباشرة أو باستخدام مصادر العلوم Gunawan, (الأخرى مثل الكتب العلمية وأهل النبات والأرصاد الجوية، 6) تعلم السلسلة الغدائية .(2004: 132-133

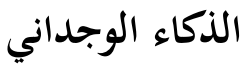
إن الذكاء الوجداني هو الذكاء الذي يرتبط بقدرة على التفكير عن المسائل الكونية، وهي وجود الإنسان وغرضه في هذا الكون وطبيعة الحياة، مثل السعادة والمأساة والمعاناة والحياة والموت، وحيث البشر بعد الموت وغيرها (134-Gunawan, 2004: 133). الذكاء الوجداني هو التعبير عن الفكر التي انبثق من داخل قلب الشخص. ويكون هذا الوعي دفعا وطاقة ورغبة للأطفال إلى بحث مواهبهم الفطرية وتطويرها (Sujiyono, 2010:63).

إن مواد البرامج التي يمكن تطويرها في الذكاء الوجداني هي تعليم الصلاة أو الثناء على الخالق، والتعويد وفقا للتعاليم الدينية، مثل التحية، والتعلم لاتباع إجراء العبادة وفقا للدين المعين، ووضع الموقف السخي وبناء التسامح تجاه الآخرين. وأما الطريقة المستخدمة لتطوير الذكاء الوجداني هي: 1) النموذج الحقيقي الذي يتجلى في كل الأعمال سواء كان شفهيا أم تحريريا، 2) من خلال القصة والحكاية التي تعبر سلوكا جيدا وسيئا، 3) الملاحظة من أدلة عظمة الخالق من الحيوانات المختلفة والنباتات المتنوعة والثروات الطبيعية الأخرى، 4) تعريف الأنشطة الدينية وجعلها نموذجا، 5) تطوير الموقف من التسامح مع الآخرين كما مخلوقات الله. يمكن أن نستخدم برنامج التحفيز لتطوير الذكاء الوجداني لدى الأطفال من خلال برامج نموذجية من الوالدين أو البالغين بحيث يتم الأطفال تعويدا على تقليد السلوك الجيد، من خلال برنامج التعويد لكي يمكن الأطفال أن يكيفوا النشاط المعين، من خلال النشاط العفوي في شكل رقابة سلوك لوك الطفل في الأنشطة اليومية والدينية المختلفة في الحياة اليومية (6ujiyono, 2010: (S3).

\section{منهجية البحث}

إن المنهج البحث المستخدم في هذا البحث هو المنهج التجريبي بالتحليل الكمي والكيفي. أن البحث التجريبي هو النوع من البحوث الذي يستخدم التجريبة في اختيار فرض معين يقرر علاقة بين عاملين أو متغيرين، وذلك عن طريق الدراسة للمواقف المتقابلة التي ضبطت كل المتغيرات ما عدا المتغير الذي يهتم الباحث بدراسة تأثيره (كاظم، 1978: 200). إن مجتمع البحث هو جميع الأفراد أو الأشخاص أو الأشياء الذين يكونون موضوع مشكلة البحث (عبيدات، 1997: 109). مجتمع هذا البحث هو جميع الطلبة في الفصل الرابع 
في مدرسة أناك صالح الابتدائية مالانج وعددها 62 طالبا. فالعينة تمثل المجتمع الأصلي وتحقق أغراض البحث ويعنى الباحث عن مشقات دراسة المجتمع الأصلي، اختارها الباحث بأساليب مختلفة وتضم عددا من الأفراد من المجتمع الأصلي (عبيدات، 1997: 110). أما عينة هذا البحث لمهارة الكلام هي 6 طلبة للمجموعة التجريبة، و 17 طالبا للمجموعة الضابطة في الفصل الرابع "أ" في مدرسة أناك صالح الابتدائية مالانج. إن أدوات البحث المستخدمة في هذا البحث هي الملاحظة، والاستبانة، والمقابلة، والاختبار. ووجود البيانات في هذا البحث هو النتائج من الملاحظة والاستبانة والمقابلة والاختبار. كانت النتيجة من الملاحظة هي المعلومات عن المدرسة التي تتكون من حالة المدرسة وحالة رئيس المدرسة والمدرسين والطلبة والوسائل التعليمية وغيرها. وأما النتيجة من الاستبانة هي أنواع متعدّد الذكاء الطلبة وأسلوب تعلمهم. وأما النتيجة من المقابلة هي تقرير الاتقان عن حالة المدرسة والأشياء التي تتعلق بها وأنواع تعدد الذكاء وما التي قد وجدت في هذا البحث. وأما النتيجة من الاختبار هي مستويات الطلبة نحو قدراتهم ومهارتهم اللغوية.

وأما أسلوب تحليل البيانات ينقسم أسلوب تحليل البيانات إلى قسمين، وهما التحليل الكيفي والكمي. أما التحليل الكيفي يستخدمه الباحث لتحليل البيانات من الاستبانة والملاحظة والمقابلة. وأما التحليل الكمي يستخدمه الباحث لتحليل البيانات من الاختبارات. إن الأسلوب المستخدم في تحليل البيانات من الاختبارات هو الرمز الإحصائي بالرمز باختبار-ت (t-test) في SPSS. nي

\section{عرض البيانات وتحليلها}

أ) عملية تدريس مهارة الكلام على ضوء نظرية الذكاءات المتعددة قد طبق الباحثان عدة حصص تدريس مهارة الكلام على ضوء نظرية الذكاءات المتعددة، ولكن على الأسف سوف بين الباحثان حصة واحدة فقط في هذا المقالة، وهي:

الخطّة الدراسية على أساس الذكاء اللغوي وأسلوب التعلّم السمعي

\section{(Lesson Plan for Word Smart and Auditory Learning Style)}

الثخصية

$$
\text { اسم الأستاذ عبد الباسط }
$$




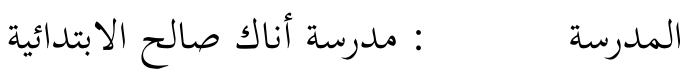

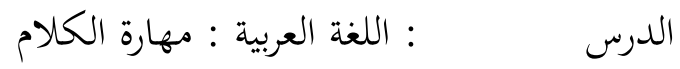

$$
\begin{aligned}
& \text { الفصل/لمرحلة : }
\end{aligned}
$$

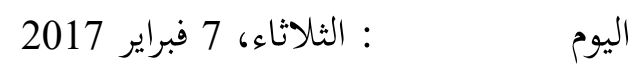

$$
\begin{aligned}
& \text { منطقة ألفى (Alfa Zone) } \\
& \text { إلقاء السلام يقابل الأستاذ الطلبة مقابلة رائعة }
\end{aligned}
$$

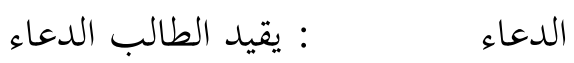

$$
\begin{aligned}
& \text { كليمات الصباح : يسأل الأستاذ عن أحوال الطلبة في هذا الصباح، ويتحدث عن الأنشطة } \\
& \text { اليومية التي عملها } \\
& \text { الطلبة بالأمس، والتي سيعملها الطلبة هذا اليوم }
\end{aligned}
$$


التشجيعات : يلقي الأستاذ التشجيعات المعروفة لدي الطلبة، على سبيل المثال: يسأل

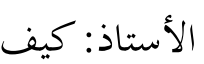

حالكم؟، ويجيب الطلبة: الحمد لله، ممتاز، تشجيع دائما، الله أكبر

المشهد الإعدادي (Scene Setting)

المسرحية البسيطة : يعمل أحمد في فندق "القاهرة" وهو موظف الاستقبال. ذات يوم، تذهب أسرة عمر إلى مصر، وتريد أن تزور الهرم وأبو الحول ونهر النيل وأليكساندريا، وفي الليل تريد أن تبيت في فندق "القاهرة"، فقابلها أحمد.

الأنثطة :

\begin{tabular}{|c|c|c|c|c|c|}
\hline \multirow{2}{*}{ التقييم } & \multirow{2}{*}{ الإجراءات } & \multicolumn{3}{|c|}{ استراتيجية } & \multirow{2}{*}{ المؤشرات } \\
\hline & & الوسائل & الطرائق & المادة & \\
\hline 1- النطق & 1- يرتّب الأستاذ مكان الطلبة. & الحاسوب & القصة & المفردة عن & 1- يقدر \\
\hline 2- المفردات اللغوية & 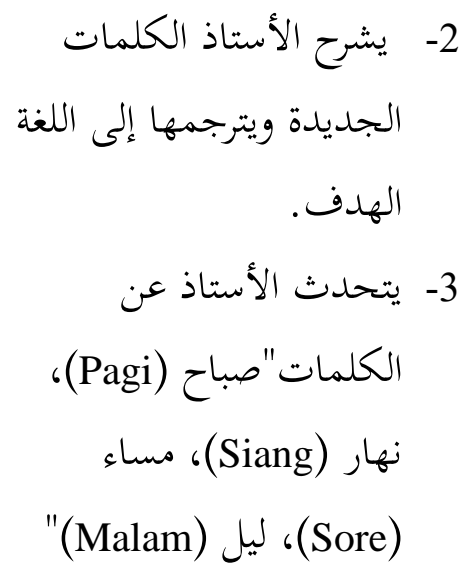 & والشاشة & القصيرة & السلام & الطلبة أن \\
\hline
\end{tabular}


تدريس مهارة الكلام في ضوء نظرية الذكاءات المتعددة...

\begin{tabular}{|c|c|c|c|c|c|}
\hline المفردات اللغوية & 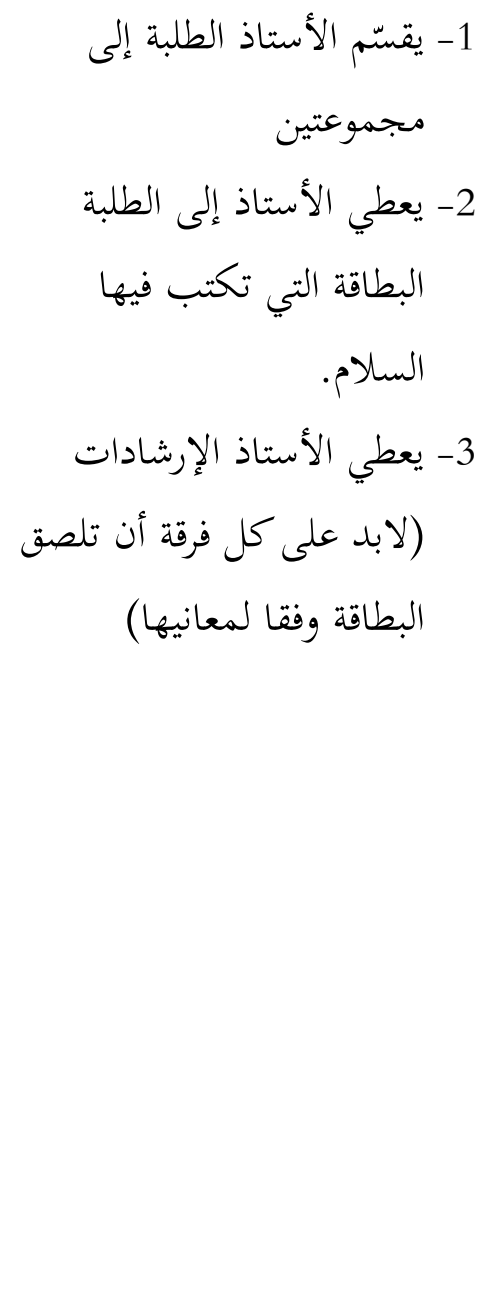 & والفطلين & 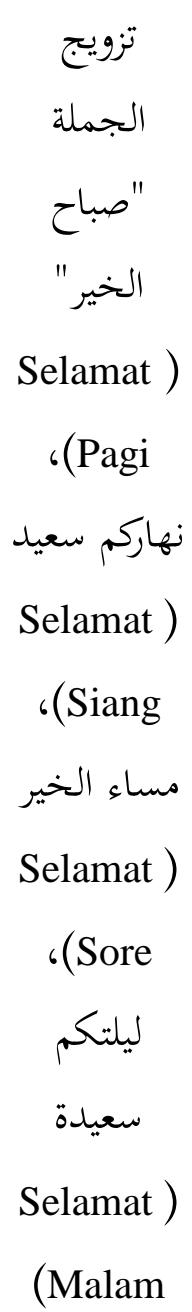 & المفردة عن & 2- \\
\hline 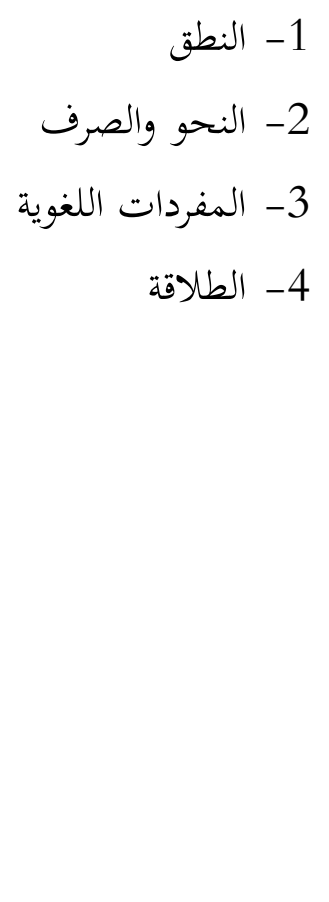 & 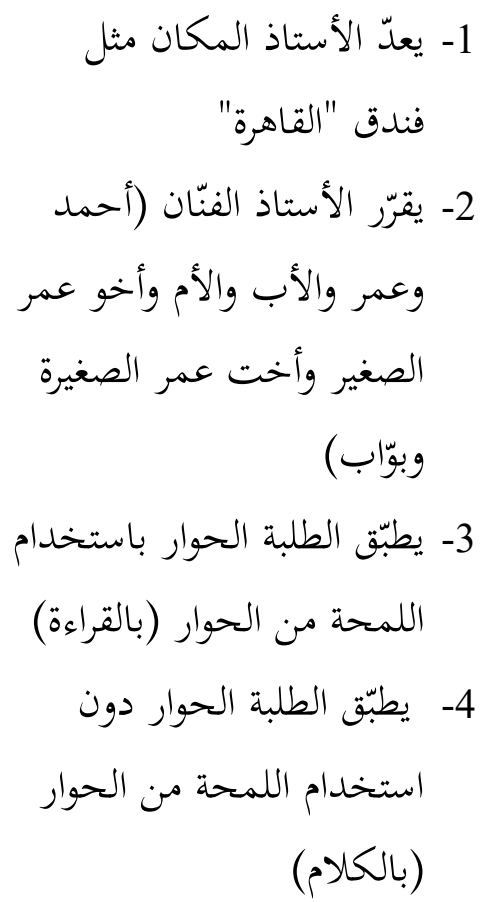 & - & التطبيق & الحوار عن & يقدر \\
\hline 1- النطق & 1- يعد الأستاذ المكان مثل & - مثيل - & التطبيق & الحوار عن & 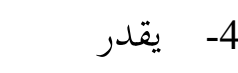 \\
\hline
\end{tabular}




\begin{tabular}{|c|c|c|c|c|c|}
\hline 2- & 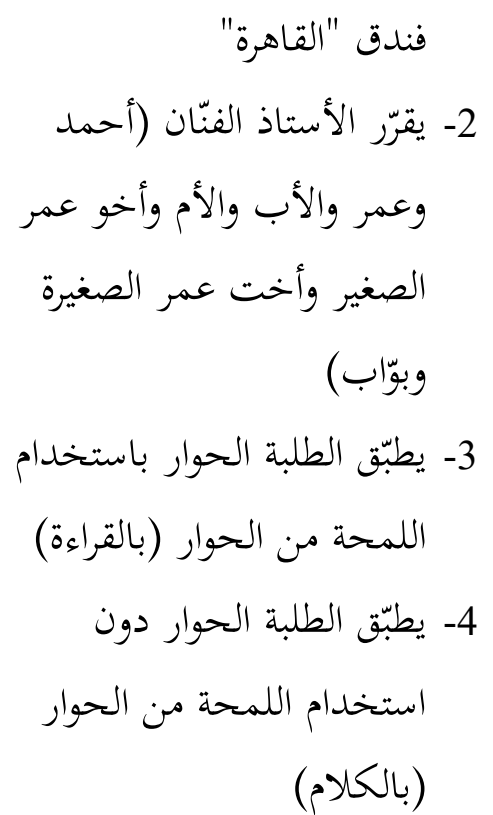 & - الأسرة & المباشر & السلام & والطلبة أن \\
\hline
\end{tabular}

لمحة الثقويم

\begin{tabular}{|c|c|c|c|}
\hline النتيجة & 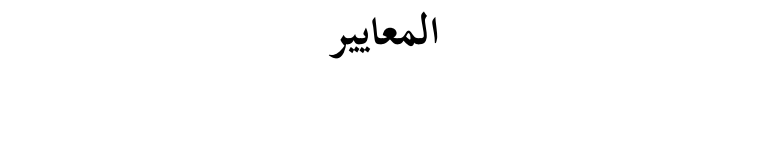 & جوانب مهارة & 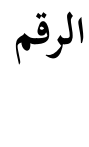 \\
\hline 25 & مفهوم تماما مع وجود لكنة خفيفة & \multirow[t]{5}{*}{ 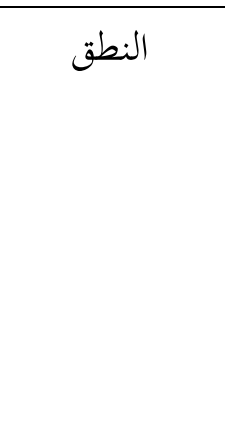 } & \multirow[t]{5}{*}{1} \\
\hline 20 & مفهوم غير بعيد مع وجود لكنة واضحة & & \\
\hline 15 & يعض أخطاء النطق وتقود إلى سوء الفهم & & \\
\hline 10 & يصعب فهمه لكثرة أخطاء النطق & & \\
\hline 5 & لا يمكن فهمه لكثرة أخطاء النطق & & \\
\hline 25 & فرتكب أخطاء نحوية وصرفية قليلة جدا لا تؤثر في & \multirow[t]{5}{*}{ النحو والصرف } & \multirow[t]{5}{*}{2} \\
\hline 20 & مع كثرة أخطاء النحوية يمكن فهم ما يعنيه تماما & & \\
\hline 15 & تيبب أخطاؤه النحوية في عدم فهم المعنى أحيانا & & \\
\hline 10 & يصعب ما يقول -إلا قليل - بسبب الأخطاء النحوية & & \\
\hline 5 & لكثرة أخطاء النحوية لا يمكن فهم أي شيئ مما & & \\
\hline 25 & يستخدم نفس المفردات التي يفضلها أهل اللغة & المفردات & 3 \\
\hline 20 & يستخدم ألفاظا غير معبرة أحيانا ولكن معنى ما يقول & اللغوية & \\
\hline
\end{tabular}




\begin{tabular}{|c|c|c|c|}
\hline & مفهوم تماما & & \\
\hline 15 & وضستخدم بعض الألفاظ الخاطئة مما تسبب في عدم & & \\
\hline 10 & قلة المفردات واستخدامه في غير السياق المناسب & & \\
\hline 5 & جهله بالكثير من المفردات والكلام غير مفهوم على & & \\
\hline 25 & يتحدث بطلاقة كأهل اللغة & \multirow[t]{5}{*}{ الطلاقة } & \multirow[t]{5}{*}{4} \\
\hline 20 & واستطاعة التعبير تماما عما يريد مع بعض الترد & & \\
\hline 15 & كثرة التردد والبطء الشديد وقد يصعب فهم ما يقول & & \\
\hline 10 & كمثرة التردد وصمته في زمن طويل حتى يصعب فهم & & \\
\hline 5 & يكمن فهم ما يقول لكثرة تردده وطول فترات الصمت & & \\
\hline
\end{tabular}

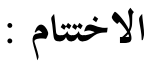

كليمات النهار : 1. يراجع الأستاذ الأنشطة التي يعملها الطلبة في ذلك اليوم، ويتكلم عن

$$
\text { الأنشطة التي سيعملها الطلبة في يوم الغد، ويشجّع }
$$

الطلبة لأن يدرسوا اللغة العربية ويعطي الكلمة البديعة مثل: أنتم ممتازون.

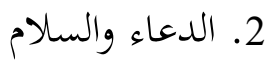

مالانج، 7 فبراير

$$
\text { رئيس المدرسة }
$$

مدرس اللغة العربية

د. شيخ الدين

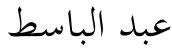

الماجستير 
ب) بيانات ننائج اختبارات مهارة الكلام

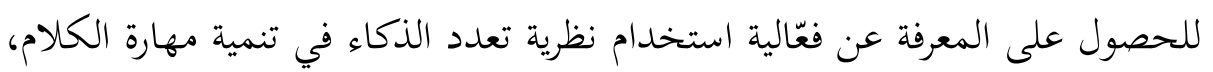

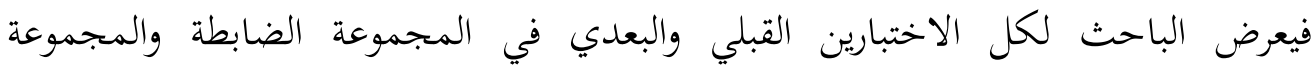

التجريبية. وأما الجدول الآتي فهو نتائج الطلبة في الاختبار القبلي في المجموعة الضابطينة:

نتائج الاختبار القبلي لمهارة الكلام للمجموعة الضابطة

\begin{tabular}{|c|c|c|c|c|c|c|c|}
\hline \multirow{2}{*}{ التقدير } & \multirow{2}{*}{ النتيجة } & \multicolumn{4}{|c|}{ جوانب الاختبار } & \multirow{2}{*}{ الأسماء } & \multirow{2}{*}{ 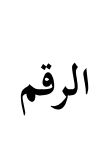 } \\
\hline & & الطلاقة & المفردات & 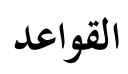 & النطق النق & & \\
\hline ضعيف & 45 & 10 & 10 & 10 & 15 & أميرة خير النساء سلسبيلة & 1 \\
\hline مقبول & 50 & 10 & 10 & 15 & 15 & أراس أسمانوسا ساكتي & 2 \\
\hline مقبول & 55 & 10 & 15 & 10 & 20 & أولياء نافيغو & 3 \\
\hline | ل متوسط & 60 & 15 & 15 & 10 & 20 & ديكرا هاعني إيدو فرايوغو & 4 \\
\hline | متوسط & 65 & 20 & 10 & 15 & 20 & فرة بلقيس مارثة & 5 \\
\hline ضعيف & 45 & 10 & 5 & 10 & 20 & فاريل أتال زين & 6 \\
\hline | ل متوسط & 65 & 15 & 20 & 15 & 15 & فرداوس أعغا فريس ريادي & 7 \\
\hline | مقبول & 55 & 15 & 20 & 10 & 10 & إلهام فيليف ذو القرنين & 8 \\
\hline ضعيف & 35 & 10 & 5 & 5 & 15 & كمال توفيق الرحمن & 9 \\
\hline ضعيف & 35 & 10 & 10 & 5 & 10 & محمد إرشاد مارتاك & 10 \\
\hline | ضعيف & 40 & 15 & 5 & 5 & 15 & محمد رفقي إرفان زركشي & 11 \\
\hline ضعيف & 45 & 15 & 5 & 10 & 15 & ناديا إفانا فيروس & 12 \\
\hline | متوسط & 65 & 15 & 15 & 15 & 20 & نوفيلة ثانية الفاتحة المدني & 13 \\
\hline | متوسط & 60 & 20 & 5 & 15 & 20 & قرة عيني جيفا واندانساري & 14 \\
\hline مقبول & 55 & 15 & 10 & 10 & 20 & سافيتري & 15 \\
\hline متوسط & 65 & 10 & 20 & 20 & 15 & سينتا نور عائشية رحمة & 16 \\
\hline ضعيف & 25 & 5 & 5 & 5 & 10 & تاقيا بيتريج ريبكا الغني & 17 \\
\hline
\end{tabular}




\begin{tabular}{|r|r|r|r|r|r|r|}
\hline المجمولع & 865 & 225 & 185 & 185 & 275 & المعدل \\
\cline { 2 - 7 } & $\mathbf{5 0} \times 88$ & $13 ، 23$ & $10 ، 88$ & $10 ، 88$ & $16 ، 17$ & \\
\hline
\end{tabular}

فمن نتائج هذا الاختبار القبلي في المجموعة الضابطة، يبدو أن الطلبة نالوا الدرجة

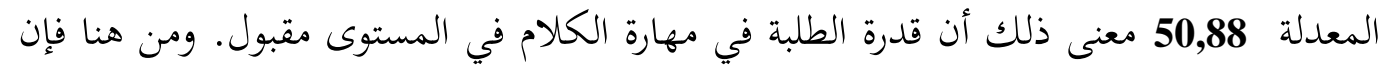
قدرة الطلبة في مهارة الكلام (الحوار أو المحادثة) بصفة عامة مقبولة.

نتيجة الاختبار القبلي لمهارة الكلام للمجموعة الضابطة

\begin{tabular}{|c|c|c|c|c|}
\hline المئوية & عدد الطلبة & التقدير & النتيجة & الرقم \\
\hline 0 & 0 & ممتاز & $100-90$ & 1 \\
\hline 0 & 0 & جيد جدا & $89-80$ & 2 \\
\hline 0 & 0 & جيد & $79-70$ & 3 \\
\hline$\% 35 ، 29$ & 6 & متوسط & $69-60$ & 4 \\
\hline$\% 23.52$ & 4 & مقبول & $59-50$ & 5 \\
\hline$\% 41 ، 17$ & 7 & ضعيف & $49-0$ & 6 \\
\hline$\% 100$ & 17 & & & المجمد \\
\hline
\end{tabular}

وجد في الجدول السابق أن بعض الطلبة في المجموعة الضابطة (29،35 \%) من عدد

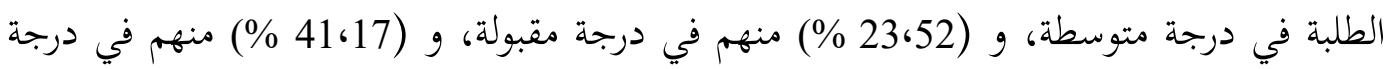
ضعيفة.

وأما الجدول الآتي فهو نتائج الطلبة في الاختبار القبلي في المجموعة التجريبية:

نتائج الاختبار القبلي لمهارة الكلام للمجموعة التجريبية

\begin{tabular}{|c|c|c|c|c|c|c|c|}
\hline \multirow[b]{2}{*}{ التقدير } & \multirow[b]{2}{*}{ النتيجة } & \multicolumn{4}{|c|}{ جوانب الاختبار } & \multirow[b]{2}{*}{ الأسماء } & \multirow[b]{2}{*}{ الرقم } \\
\hline & & الطلاقة & المفردا & القواعد & النطق & & \\
\hline مقبول & 55 & 15 & 5 & 15 & 20 & دوينا رزقي وشيدة & 1 \\
\hline مقبول & 50 & 15 & 5 & 10 & 20 & فكري أحمد دأني & 2 \\
\hline جيد & 70 & 15 & 20 & 15 & 20 & رضا فهريزا رهاوارين & 3 \\
\hline
\end{tabular}




\begin{tabular}{|c|c|c|c|c|c|c|c|}
\hline ضعيف & 45 & 10 & 10 & 10 & 15 & فوتريبية أوريليا هدى & 4 \\
\hline متوسط & 65 & 15 & 20 & 15 & 15 & أيو نبيلة رمضان & 5 \\
\hline مقبول & 50 & 15 & 15 & 10 & 10 & سلسبيلة يسمين دوي & 6 \\
\hline \multirow{2}{*}{ مقبول } & 335 & 85 & 75 & 75 & 100 & \multicolumn{2}{|c|}{ المجموع } \\
\hline & $55 \cdot 83$ & 14616 & $12 \cdot 5$ & $12 \cdot 5$ & $16 \cdot 66$ & \multicolumn{2}{|c|}{ المعدل } \\
\hline
\end{tabular}

فمن نتائج هذا الاختبار القبلي في المجموعة التجريبية، يبدو أن الطلبة نالوا الدرجة المعدلة 55,83 معنى ذلك أن قدرة الطلبة في مهارة الكلام في المستوى مقبول. ومن هنا فإن قدرة الطلبة في مهارة الكلام (الحوار أو المحادثة) بصفة عامة مقبولة.

\section{نتيجة الاختبار القبلي لمهارة الكلام للمجموعة التجريبية}

\begin{tabular}{|c|c|c|c|c|}
\hline المئوية & عدد الطلبة & التقدير & النتيجة & الرقم \\
\hline 0 & 0 & ممتاز & $100-90$ & 1 \\
\hline 0 & 0 & جيد جدا & $89-80$ & 2 \\
\hline$\% 16 \cdot 66$ & 1 & جيد & $79-70$ & 3 \\
\hline$\% 16 \cdot 66$ & 1 & متوسط & $69-60$ & 4 \\
\hline$\% 50$ & 3 & مقبول & $59-50$ & 5 \\
\hline$\% 16.66$ & 1 & ضعيف & $49-0$ & 6 \\
\hline$\% 100$ & 6 & & & المجه \\
\hline
\end{tabular}

وجد في الجدول السابق أن بعض الطلبة في المجموعة التجريبية (66،16 \%) من عدد الطلبة في درجة جيد، و (66،16 \%) منهم في درجة متوسطة، و (50 \%) منهم في درجة مقبولة،

$$
\text { و (16،66 \%) في درجة ضعيفة. }
$$

المقارنة بين نتيجة الاختبار القبلي لمهارة الكلام للمجموعة الضابطة والتجريبية

\begin{tabular}{|c|c|c|c|c|c|c|}
\hline \multicolumn{2}{|c|}{ المجموعة التجريبية } & \multicolumn{2}{|c|}{ المجموعة الضابطة } & \multirow{3}{*}{ التقدير } & \multirow{3}{*}{ النتيجة } & \multirow{3}{*}{ الرقم } \\
\hline النسبة & عدد الطلبة & النسبة & عدد الطلبة & & & \\
\hline المئوية & & المئوية & & & & \\
\hline
\end{tabular}




\begin{tabular}{|c|c|c|c|c|c|c|}
\hline 0 & 0 & 0 & 0 & ممتاز & $100-90$ & 1 \\
\hline 0 & 0 & 0 & 0 & جدد & $89-80$ & 2 \\
\hline & & & & & & \\
\hline$\% 16.66$ & 1 & 0 & 0 & جيد & $79-70$ & 3 \\
\hline$\% 16.66$ & 1 & $\% 35.29$ & 6 & متوسط & $69-60$ & 4 \\
\hline$\% 50$ & 3 & $\% 23.52$ & 4 & مقبول & $59-50$ & 5 \\
\hline$\% 16 \cdot 66$ & 1 & $\% 41.17$ & 7 & ضعنف & $49-0$ & 6 \\
\hline$\% 100$ & 6 & $\% 100$ & 17 & & & \\
\hline
\end{tabular}

اعتمادا على الجدول السابق يوجد أن الطالب الواحد من المجموعة التجريبية حصل

على درجة جيد، 6 طلبة من المجموعة الضابطة والطالب الواحد من المجموعة التجريبية حصلوا على درجة متوسطة، 4 طلبة من المجموعة الضابطة و 3 طلبة من المجموعة التجريبية حصلوا على درجة مقبولة، و 7 طلبة من المجموعة الضابطة والطالبة الواحدة من المجموعة التجريبية حصلوا على درجة ضعيفة.

وبالتالي قدم الباحث نتائج الاختبار البعدي للمجموعة الضابطة : نتائج الاختبار البعدي لمهارة الكلام للمجموعة الضابطة

\begin{tabular}{|c|c|c|c|c|c|c|c|}
\hline \multirow{2}{*}{ التقدير } & \multirow{2}{*}{ النتيجة } & \multicolumn{4}{|c|}{ جوانب الاختبار } & \multirow{2}{*}{ الأسماء } & \multirow{2}{*}{ 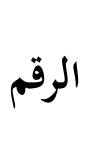 } \\
\hline & & الطلاقة & المفردات & القواعد القد & النطق النق & & \\
\hline مقبول & 50 & 10 & 15 & 10 & 15 & أميرة خير النساء سلسبيلة & 1 \\
\hline مقبول & 50 & 5 & 20 & 10 & 15 & أراس أسمانوسا ساكتي & 2 \\
\hline ضعيف & 35 & 5 & 5 & 5 & 20 & أولياء نافيغو & 3 \\
\hline ضعيف & 45 & 10 & 15 & 5 & 15 & ديكرا هاعغي إيدو فرايوغو & 4 \\
\hline متوسط & 65 & 15 & 20 & 10 & 20 & فرة بلقيس مارثة & 5 \\
\hline ضعيف & 30 & 10 & 5 & 5 & 10 & فاريل أتال زين & 6 \\
\hline متوسط & 60 & 15 & 15 & 10 & 20 & فرداوس أعغا فريس ريادي & 7 \\
\hline ضعيف & 45 & 10 & 10 & 10 & 15 & إلهام فيليف ذو القرنين & 8 \\
\hline ضعيف & 20 & 5 & 5 & 5 & 5 & كمال توفيق الرحمن & 9 \\
\hline ضعيف & 45 & 5 & 15 & 10 & 15 & محمد إرشاد مارتاك & 10 \\
\hline
\end{tabular}




\begin{tabular}{|c|c|c|c|c|c|c|c|}
\hline ضعيف & 20 & 5 & 5 & 5 & 5 & محمد رفقي إرفان زركشي & 11 \\
\hline ضعيف & 20 & 5 & 5 & 5 & 5 & ناديا إفانا فيروس & 12 \\
\hline متوسط & 65 & 15 & 15 & 20 & 15 & نوفيلة ثانية الفاتحة المدني & 13 \\
\hline ضعيف & 25 & 5 & 5 & 5 & 10 & قرة عيني جيفا واندانساري & 14 \\
\hline ضعيف & 45 & 10 & 10 & 10 & 15 & سافيتري & 15 \\
\hline متوسط & 65 & 15 & 20 & 15 & 15 & سينتا نور عائشية رحمة & 16 \\
\hline ضعيف & 25 & 5 & 5 & 5 & 10 & تاقيا بيتريج ريبكا الغني & 17 \\
\hline & 755 & 150 & 190 & 145 & 225 & \multicolumn{2}{|c|}{ المجموع } \\
\hline & $44 ، 41$ & $8 \cdot 82$ & $11 \cdot 17$ & $8 \cdot 52$ & $13 \cdot 23$ & \multicolumn{2}{|c|}{ المعدل } \\
\hline
\end{tabular}

فمن نتائج هذا الاختبار البعدي في المجموعة الضابطة، ظهر أن الطلبة نالوا الدرجة المعدلة 44,41 معنى ذلك أن قدرة الطلبة في مهارة الكلام في المستوى ضعيف. ومن هنا فإن قدرة الطلبة في مهارة الكلام بصفة عامة ضعيفة. نتيجة الاختبار البعدي لمهارة الكلام للمجموعة الضابطة

\begin{tabular}{|c|c|c|c|c|}
\hline \multicolumn{2}{|c|}{ الفصل الضابط } & \multirow{2}{*}{ التقدير } & \multirow{2}{*}{ النتيجة } & \multirow{2}{*}{ الرقم } \\
\hline النسبة المئوية & عدد الطلبة & & & \\
\hline 0 & 0 & ممتاز & $100-90$ & 1 \\
\hline 0 & 0 & جيد جدا & $89-80$ & 2 \\
\hline 0 & 0 & جيد & $79-70$ & 3 \\
\hline$\% 23.52$ & 4 & متوسط & $69-60$ & 4 \\
\hline$\% 11.76$ & 2 & مقبول & $59-50$ & 5 \\
\hline$\% 64670$ & 11 & ضعيف & $49-0$ & 6 \\
\hline$\% 100$ & 17 & & & \\
\hline
\end{tabular}

نظرا إلى الجدول السابق، يوضح لنا أن (52،23 \%) من الطلبة في المجموعة الضابطة حصلوا على درجة متوسطة، و (76، 11\% ) منهم حصلوا على درجة مقبولة، و (70،64 \%) مهنم حصلوا على درجة ضعيفة. وبالتالي قدم الباحث نتائج الاختبار البعدي للمجموعة التجريبية: 
نتائج الاختبار البعدي لمهارة الكلام للمجموعة التجريبية

\begin{tabular}{|c|c|c|c|c|c|c|c|}
\hline \multirow{2}{*}{ التقدير } & \multirow{2}{*}{ النتيجة } & \multicolumn{4}{|c|}{ جوانب الاختبار } & \multirow{2}{*}{ الأسماء } & \multirow{2}{*}{ 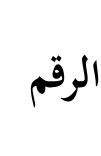 } \\
\hline & & الطلاقة & المفردات & القواعد & النطق & & \\
\hline جيد & 70 & 20 & 15 & 15 & 20 & دوينا رزقي وشيدة & 1 \\
\hline جيد & 75 & 20 & 20 & 15 & 20 & فكري أحمد دأني & 2 \\
\hline ممتاز & 90 & 25 & 25 & 20 & 20 & رضا فهريزا رهاوارين & 3 \\
\hline جيد جدا & 80 & 20 & 25 & 20 & 15 & فوتري & 4 \\
\hline جيد & 75 & 20 & 20 & 15 & 20 & أيو نبيلة رمضان & 5 \\
\hline جيد جدا & 85 & 25 & 20 & 20 & 20 & سلسبيلة يسمين دوي & 6 \\
\hline \multirow{2}{*}{ جيد } & 475 & 130 & 125 & 105 & 115 & \multicolumn{2}{|c|}{ المجموع } \\
\hline & $79 ، 16$ & $21 ، 66$ & $20 ، 83$ & $17 \cdot 5$ & $19 ، 16$ & \multicolumn{2}{|r|}{ المعدل } \\
\hline
\end{tabular}

فمن نتائج هذا الاختبار البعدي في المجموعة التجريبة، ظهر أن الطلبة نالوا الدرجة

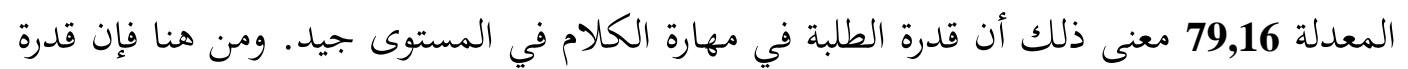
الطلبة في مهارة الكلام بصفة عامة جيدة. جدول 11

نتيجة الاختبار البعدي لمهارة الكلام للمجموعة التجريبية

\begin{tabular}{|c|c|c|c|c|}
\hline \multicolumn{2}{|c|}{ الفصل التجريبي } & \multirow{2}{*}{ التقدير } & \multirow{2}{*}{ النتيجة } & \multirow{2}{*}{ الرقم } \\
\hline النسبة المئوية & عدد الطلبة & & & \\
\hline$\% 16.66$ & 1 & ممتاز & $100-90$ & 1 \\
\hline$\% 33.33$ & 2 & جيد جدا & $89-80$ & 2 \\
\hline$\% 50$ & 3 & جيد & $79-70$ & 3 \\
\hline 0 & 0 & متوسط & $69-60$ & 4 \\
\hline 0 & 0 & مقبول & $59-50$ & 5 \\
\hline 0 & 0 & ضعيف & $49-0$ & 6 \\
\hline$\% 100$ & 6 & & & المجد \\
\hline
\end{tabular}


نظرا إلى الجدول السابق، يوضح لنا أن (66،16 \%) من الطلبة في المجموعة التجريبية حصل على درجة ممتازة، و (33،33 \%) منهم حصلوا على درجة جيد جدا، و (50 \%) مهنم حصلوا على درجة جيدة.

المقارنة بين نتيجة الاختبار البعدي لمهارة الكام للمجموعة الضابطة والتجريبية

\begin{tabular}{|c|c|c|c|c|c|c|}
\hline \multicolumn{2}{|c|}{ الفصل التجريبي } & \multicolumn{2}{|c|}{ الفصل الضابط } & \multirow{3}{*}{ التقدير } & \multirow{3}{*}{ النتيجة } & \multirow{3}{*}{ الرقم } \\
\hline النسبة & عدد & النسبة & عدد & & & \\
\hline المئوية & الطلبة & المئوية & الطلبة & & & \\
\hline$\% 16 \cdot 66$ & 1 & 0 & 0 & ممتاز & $100-90$ & 1 \\
\hline$\% 33.33$ & 2 & 0 & 0 & جيد جدا & $89-80$ & 2 \\
\hline$\% 50$ & 3 & 0 & 0 & جيد & $79-70$ & 3 \\
\hline 0 & 0 & $\% 23.52$ & 4 & متوسط & $69-60$ & 4 \\
\hline 0 & 0 & $\% 11.76$ & 2 & مقبول & $59-50$ & 5 \\
\hline 0 & 0 & $\% 64670$ & 11 & ضعيف & $49-0$ & 6 \\
\hline$\% 100$ & 6 & $\% 100$ & 17 & & & \\
\hline
\end{tabular}

اعتمادا على الجدول السابق يوجد أن الطالب الواحد من المجموعة التجريبية حصل على درجة ممتازة، والطالبان من المجموعة التجريبية حصلا على درجة جيدة جدا، و 3 طلبة من المجموعة التجريبية حصلوا على درجة جيدة، و 4 طلبة من المجموعة الضابطة حصلوا على درجة متوسطة، والطالبان من المجموعة الضابطة حصلا على درجة مقبولة، و 11 طالبا من المجموعة الضابطة حصلوا على درجة ضعيفة.

2) المبحث الثاني: تحليل بيانات نتائج البحث لمهارة الكالام وتفسيرها قد وصل الباحث إلى تحليل البيانات بتحليل نتيجة الاختبار القبلي والبعدي لمهارة الكلام للمجموعة الضابطة والتجريبية، وتحليل المقارنة بين هاتين المجموعتين، كلاهما لنيل البيانات

$$
\text { ويتبع الباحث في عملية التحليل الخطوات التالية : }
$$

أ) تحليل نتيجة البحث من الاختبار القبلي والبعدي لمهارة الكلام للمجموعة الضابطة

$$
\text { والتجريبة }
$$

لمعرفة التأثير بين المتغير التجريبي والناتج في مهارة الكلام، حلل الباحث نتيجة الاختبار القبلي والبعدي للمجموعة الضابطة والتجريبية باستخدام اختبار- ت (t-test)

$$
\text { في SPSS وأما النتيجة هي: وليني }
$$


نتيجة البحث من الاختبار القبلي والبعدي لمهارة الكلام للمجموعة الضابطة

Paired Samples Statistics

\begin{tabular}{|c|c|c|c|c|c|}
\hline & & Mean & $\mathrm{N}$ & Std. Deviation & $\begin{array}{c}\text { Std. Error } \\
\text { Mean }\end{array}$ \\
\hline \multirow{2}{*}{$\begin{array}{l}\text { Pair } \\
1\end{array}$} & post test & 41.7647 & 17 & 16.38799 & 3.97467 \\
\hline & pre test & 50.8824 & 17 & 12.27743 & 2.97771 \\
\hline
\end{tabular}

Paired Samples Correlations

\begin{tabular}{|c|c|c|c|}
\hline & $\mathrm{N}$ & Correlation & Sig. \\
\hline Pair 1 post test \& pre test & 17 & .691 & .002 \\
\hline
\end{tabular}

\section{Paired Samples Test}

\begin{tabular}{|c|c|c|c|}
\hline & & & Pair 1 \\
\hline & & & post test - pre test \\
\hline \multirow[t]{5}{*}{ Paired Differences } & Mean & & -9.11765 \\
\hline & Std. Deviation & & 11.88950 \\
\hline & Std. Error Mean & & 2.88363 \\
\hline & 95\% Confidence Interval & Lower & -15.23067 \\
\hline & of the Difference & Upper & -3.00463 \\
\hline $\mathrm{t}$ & & & -3.162 \\
\hline df & & & 16 \\
\hline Sig. (2-tailed) & & & .006 \\
\hline
\end{tabular}

قد اتضح من الجدول السابق نتيجة اختبار-ت (t-test) لعينة مزاوجة (الاختبار

القبلي والبعدي) في بيانات مهارة الكام للمجموعة الضابطة. كانت درجة ت-حساب

(thitung)

|thitung > tabel مي 2,11. فعرف الباحث أن درجة ت-حساب أصغر من درجة ت-جدول

. $(3,162>2,086)$

اعتمادا على حساب النتيجة الأخيرة ليس فيه الاختلاف بين نتيجة الاختبار القبلي

والبعدي للمجموعة الضابطة بالطريقة التقليدية. معنى ذلك أن تطبيق الطريقة التقليدية لاتئثر

تأثيرا تفاعليا في تنمية مهارة الكلام.

نتيجة البحث من الاختبار القبلي والبعدي لمهارة الكلام للمجموعة التجريبية 
Paired Samples Statistics

\begin{tabular}{|c|c|c|c|c|c|}
\hline & & Mean & $\mathrm{N}$ & Std. Deviation & $\begin{array}{c}\text { Std. Error } \\
\text { Mean }\end{array}$ \\
\hline \multirow{2}{*}{$\begin{array}{l}\text { Pair } \\
1\end{array}$} & post test & 79.1667 & 6 & 7.35980 & 3.00463 \\
\hline & pre test & 55.8333 & 6 & 9.70395 & 3.96162 \\
\hline
\end{tabular}

Paired Samples Correlations

\begin{tabular}{|lr|r|r|r|}
\hline & $\mathrm{N}$ & Correlation & \multicolumn{1}{c|}{ Sig. } \\
\hline Pair 1 post test \& pre test & 6 & .292 & .575 \\
\hline
\end{tabular}

Paired Samples Test

\begin{tabular}{|c|c|c|c|}
\hline & & & Pair 1 \\
\hline & & & post test - pre test \\
\hline \multirow[t]{5}{*}{ Paired Differences } & Mean & & 23.33333 \\
\hline & Std. Deviation & & 10.32796 \\
\hline & Std. Error Mean & & 4.21637 \\
\hline & $95 \%$ Confidence Interval & Lower & 12.49481 \\
\hline & of the Difference & Upper & 34.17186 \\
\hline $\mathrm{t}$ & & & 5.534 \\
\hline df & & & 5 \\
\hline Sig. (2-tailed) & & & .003 \\
\hline
\end{tabular}

قد اتضح من الجدول السابق نتيجة اختبار-ت (t-test) لعينة مزاوجة (الاختبار

القبلي والبعدي) في بيانات مهارة الكلام للمجموعة التجريبية. كانت ت-حساب (thitung)

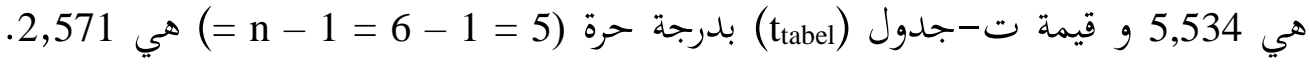

فعرف الباحث أن ت-حساب أكبر من ت-جدول ت 2,571 > thitung > tabel

اعتمادا على حساب النتيجة الأخيرة هناك فرق ظاهر بين نتيجة الاختبار القبلي

والبعدي للمجموعة التجريبية. معنى ذلك أن تطبيق تطبيق نظرية تعدد الذكاء فعّال لتنمية

مهارة الكلام.

وأما الجدول التالي دلالة الفرق بين المجموعة الضابطة والتجريبية للاختبار القبلي والبعدي في مهارة الكاملام:

دلالة الفرق بين نتائج البحث من الاختبار القبلي والبعدي لمهارة الكلام للمجموعة الضابطة

والتجريبية

\begin{tabular}{|c|c|c|c|c|c|c|c|}
\hline \multicolumn{7}{|c|}{ الاختباران القبلي و البعدي } & \multirow{3}{*}{$\begin{array}{c}\overline{3} \\
\vdots \\
\vdots \\
\vdots \\
\vdots\end{array}$} \\
\hline درجة تاء في الجدول & د. ف & قيمة & قيمة ت & الخطأ & الانحراف & متوسط & \\
\hline عند مستوى الدلالة & $(\mathrm{N}-1)$ & 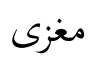 & ( $\left.t_{\text {hitung }}\right)$ & المعياري & المعياري & 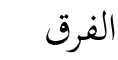 & \\
\hline
\end{tabular}




\begin{tabular}{|c|c|c|c|c|c|c|c|c|}
\hline $5 \%$ & $1 \%$ & & & & & & & \\
\hline 2,29 & 2,11 & 16 & 0,006 & $-3,162$ & 2,88 & 11,88 & $-9,11$ & الضابطة \\
\hline 4,30 & 2,57 & 5 & 0,003 & 5,534 & 4,21 & 10,32 & 23,33 & التجريبية \\
\hline
\end{tabular}

نظرا إلى نتيجة الاختبار القبلي والبعدي من كل مجموعة، قد اتضح للباحث أن هناك

فرق لدلالة إحصائية من كل جهة حيث بلغت درجة تاء 3,162- للمجموعة الضابطة، هذا

العدد أصغر من درجة تاء في الجدول عند مستوى الدلالة 5\% و 1\%. وأما درجة تاء 5,534

للمجموعة التجريبية أكبر من درجة تاء في الجدول مستوى الدلالة 5\% و 1\%. معنى ذلك

أن تطبيق نظرية تعدد الذكاء له أكثر تفعيل النتيجة من الطريقة التقليدية لتنمية مهارة الكلام.

ب) تحليل نتيجة البحث من الاختبار البعدي لمهارة الكلام للحصول على المقارنة بين

المجموعة الضابطة والتجريبية

اعتمد الباحث أن يحلل نتيجة الاختبار البعدي وحدها في مهارة الكلام، لأنها

مقياس لمعرفة تأثير المتغير التابع في المجموعة الضابطة والمتغير التجريبي في المجموعة

التجريبية. وحلل الباحث باستخدام اختبار - ت (t-test) في SPSS ـ وأما النتيجة هي:

المقارنة بين نتيجة البحث من الاختبار البعدي لمهارة الكلام للمجموعة الضابطة والتجريبية

Group Statistics

\begin{tabular}{|ll|r|r|r|r|}
\hline & group & $\mathrm{N}$ & Mean & Std. Deviation & $\begin{array}{c}\text { Std. Error } \\
\text { Mean }\end{array}$ \\
\hline Kemampuan Bicara & Kontrol & 34 & 46.3235 & 14.99034 & 2.57082 \\
& Eksperimen & 12 & 67.5000 & 14.69385 & 4.24175 \\
\hline
\end{tabular}

Independent Samples Test

\begin{tabular}{|c|c|c|c|c|}
\hline & & & \multicolumn{2}{|c|}{ Kemampuan Bicara } \\
\hline & & & $\begin{array}{c}\text { Equal variances } \\
\text { assumed }\end{array}$ & $\begin{array}{c}\text { Equal variances } \\
\text { not assumed }\end{array}$ \\
\hline \multirow{9}{*}{$\begin{array}{l}\text { Levene's Test for } \\
\text { Equality of Variances } \\
\text { t-test for Equality of } \\
\text { Means }\end{array}$} & \multicolumn{2}{|l|}{$\mathrm{F}$} & .005 & \\
\hline & \multicolumn{2}{|l|}{ Sig. } & .942 & \\
\hline & \multicolumn{2}{|l|}{$\mathrm{t}$} & -4.228 & -4.269 \\
\hline & \multicolumn{2}{|l|}{ df } & 44 & 19.680 \\
\hline & \multicolumn{2}{|l|}{ Sig. (2-tailed) } & .000 & .000 \\
\hline & \multicolumn{2}{|l|}{ Mean Difference } & -21.17647 & -21.17647 \\
\hline & \multicolumn{2}{|l|}{ Std. Error Difference } & 5.00868 & 4.96000 \\
\hline & \multirow{2}{*}{$\begin{array}{l}95 \% \text { Confidence Interval } \\
\text { of the Difference }\end{array}$} & Lower & -31.27081 & -31.53362 \\
\hline & & Upper & -11.08213 & -10.81932 \\
\hline
\end{tabular}

اعتمادا على الجدول السابق وجدت نتيجة اختبار-ت لعينة مستقيلة في بيانات

مهارة الكلام في الاختبار البعدي بين المجموعة الضابطة والتجريبة. وفي الخطوة الأولى، 
قام الباحث باختبار لفين (Levene-Test) لمعرفة "هل الافتراض (Assume) من عينة المجموعة الضابطة والتجريبية متساو أو متفرق (في كبارها) مملوءة أو غير مملوءة،" باستخدام الفرضية (Hypothesis):

$$
\begin{gathered}
H_{0}: \sigma_{1}^{2}=\sigma_{2}^{2} \\
H_{1}: \sigma_{1}^{2} \neq \sigma_{2}^{2}
\end{gathered}
$$

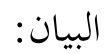

$\sigma_{1}^{2}=$ ragam perlakuan kontrol

$\sigma_{2}^{2}=$ ragam perlakuan eksperimen

من الحساب السابق قد حصلت على النتيجة أن قيمة مغزى ( significant 0,942 أكبر من مalue الضابطة والتجريبية كبيرة.

أما الخطوة الثانية، نظرا إلى نتيجة اختبار لفين (Levene-Test) وجديدة وأن أن الافتراض من المجموعة الضابطة والتجريبية كبير، فحسب تلك النتيجة باستخدام اختبار- ت (t-test) في SPSS بافتراض (assume) أن نتيجة المجموعة الضابطة والتجريبية متساوتين (equal variance assume). من الحساب السابق قد حصلت على النتيجة أن قيمة ت-حساب (thitung) هي 4,228- و قيمة ت-جدول (tabel

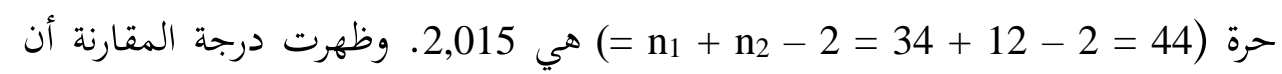
0,000 (signification value) قيمة مغزى أصغر من المجموعة الضابطة والتجريبية غير متساوية.

اعتمادا على حساب النتيجة الأخيرة عرف الباحث أن هناك فرق ظاهر بين نتيجة الاختبار البعدي للمجموعة الضابطة والتجريبية بعد تجريبة نظرية تعدد الذكاء. وبعبارة أخرى أن استخدام نظرية تعدد الذكاء فعّال لتنمية مهارة الكلام.

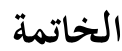

بعد تجريبة استخدام نظرية الذكاءات المتعددة في تعليم مهارة الكلام في مدرسة أناك صالح الابتدائية شارع أرومبا رقم 31 مالانج، قد وصل الباحث إلى الاستنتاج الأخير والنتائج التي وصل إليها الباحث في هذه الدراسة تتلخص فيما يلي: 
1. عملية تدريس مهارة الكلام على ضوء نظرية الذكاءات المتعددة في مدرسة أناك صالح الابتدائية تعتبر في الخطة الدراسية التي تشمل على وصف الشخصية المدرس، والمقرر

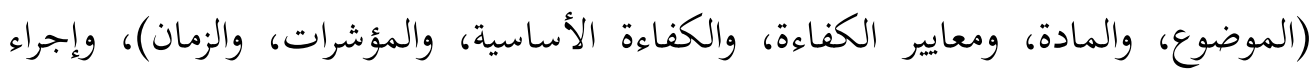

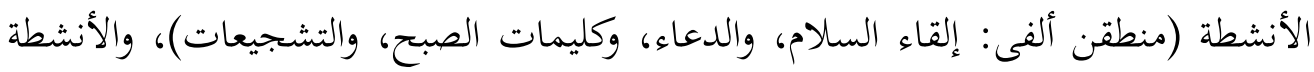
(المؤشرات، والاستراتيجيات: المادة، والطرائق، والوسائل)، والإجراءات، والتقييم: جوانب التباتيات مهارة الكلام، والمعايير، والنتيجة)، والاختتام.

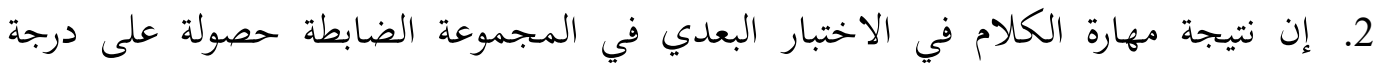
معدلة 41,76، ومتوسط الفرق 9,11-، والانحراف المعياري 16,38، والخطأ المعياري 3,97،

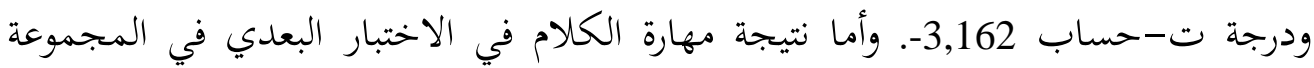
التجريبية حصولة على درجة معدلة 79,16، ومتوسط الفرق 23,33، والانحراف المعياري

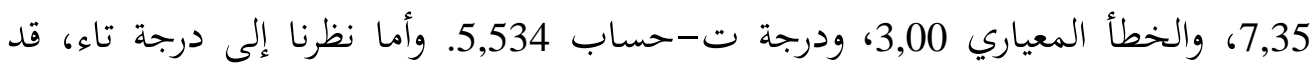

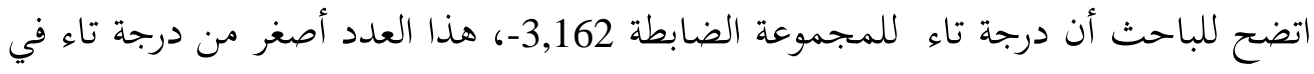
الجدول عند مستوى الدلالة 5\% و 1\%، وأما درجة تاء للمجموعة التجريبة 5,534، هذا

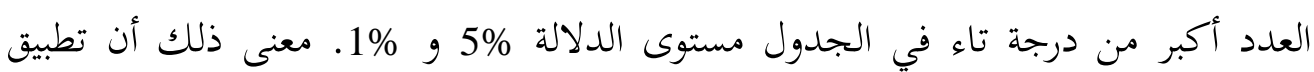
نظرية تعدّد الذكاءات فعّال لتنمية مهارة الكلام.

\section{قائمة المراجع}

عبيدات، ذوقان، وعبد الرحمن عدس، وكايد عبد الحق. 1997. البحث العلمى مفهومه، أدواته، أساليبه، الرياض: دار أسامة للنشر والتوزيع.

عليان، أحمد فؤاد. 1992. المهارات اللغوية ماهيتها وطرائق تلدريسها ـ الرياض: دار المسلم.

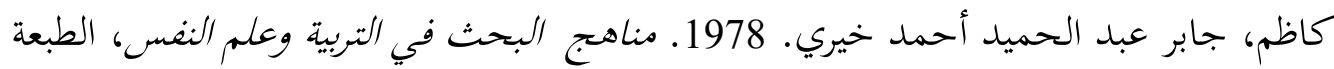
الثانية. مصر: دار النهضة العربية.

Armstrong, Thomas. 2005. In Their Own Way: Discovering and Encouraging Your Child's

Multiple Intellegences. Terj. Rina Buntaran. Setiap Anak Cerdas! Panduan Membantu Anak

Belajar dengan Memanfaatkan Multiple Intelligences-nya. Cet. 3. Jakarta: Gramedia

Pustaka Utama.

Armstrong, Thomas. 2002. Multiple Intelligences in the Classroom-2 ${ }^{\text {nd }}$ edition. Terj. Yudhi 
Murtanto. Sekolah Para Juara: Menerapkan Multiple Intelligences di Dunia Pendidikan.

Cet. 1. Bandung: Kaifa.

Armstrong, Thomas. 2002. Seven Kinds of Smart: Identifying and Developing Your Multiple

Intelligences. Terj. T. Hermaya. Seven Kinds of Smart: Menemukan dan Meningkatkan

Kecerdasan Anda Berdasarkan Teori multiple Intelligence. Cet. 2. Jakarta: PT. Gramedia

Pustaka Utama.

Campbell, Linda, Bruce Campbell, dan Dee Dickinson. 2004. Teaching and Learning Through

Multiple Intelligences. Terj. Tim Intuisi. Metode Praktis Pembelajaran Berbasis Multiple

Intelligences. Cet. 1. Depok: Intuisi Press.

Efendi, Agus. 2005. Revolusi Kecerdasan Abad 21: Kritik MI, EI, SQ, AQ, dan Successful

Intelligence Atas IQ. Bandung: Alfabeta.

Eggen, P. dan D. Kauchak, 2004. Educational Psychology: Windows of Classroom. Upper Saddle

River, New Jersey: Pearson Education, Inc. p.199.

Gardner, Howard. 1993. Multiple Intelligences: The Theory and Practice. New York: BasicBooks.

Gardner, Howard. 2003. Multiple Intelligences. Terj. Alexander Sindoro. Kecerdasan

Majemuk:Teori dalam Praktek. Batam: Interaksara.

Gunawan, Adi W. 2004. Genius Learning Strategy: Petunjuk Praktis untuk Menerapkan

Accelerated Leraning. Jakarta: PT. Gramedia Pustaka Utama.

Hakim, Thursan. 2005. Belajar Secara Efektif. Jakarta: Puspa Swara.

Muhaimin dan Abdul Mujib. 1993. Pemikiran pendidikan Islam: Kajian Filosofis dan Kerangka

Dasar Operasionalisasinya. Bandung: TrigendaKarya

Musfiroh, Tadkiroatun. 2008. Cerdas Melalui Bermain: Cara Mengasah Multiple Intelligences

Anak Sejak Usia Dini. Jakarta: Grasindo.

Sujiono, Yuliani Nurani dan Bambang Sujiono. 2010. Bermain Kreatif Berbasis Kecerdasan

Jamak. Cet. 1. Jakarta: PT. Indeks.

Uno, Hamzah B. dan Masri Kuadrat Umar. 2010. Mengelola Kecerdasan dalam Pembelajaran: Bumi Aksara.

Sebuah Konsep Pembelajaran Berbasis Kecerdasan. Ed. 1. Cet. 2. Jakarta: 